\title{
Conferência do \\ Professor Dr. Diogo Freitas do Amaral, Catedrático de Direito Administrativo da Faculdade de Direito da Universidade de Lisboa, sobre A Evolução do Direito Administrativo em Portugal Nos Últimos Dez Anos, Proferida aos 21 de Agosto de 1985, na Faculdade de Direito da Universidade de São Paulo(*)
}

\section{SENHORES PROFESSORES E ESTUDANTES}

e com muita honra e com o maior prazer que aqui venho hoje falar-vos sobre a evolução do Direito Administrativo em Portugal nos últimos dez anos. São várias as razões pelas quais sinto grande júbilo em aqui estar. Em primeiro lugar, por encontrar-me no Brasil, grande País irmão de Portugal, que os portugueses sempre visitam com sentimentos de emoção, de admiração e de respeito. Em segundo lugar, por estar de visita a São Paulo, portentosa Cidade cheia de vida, de progresso, de riqueza e também poderoso centro de criação científica e de irradiação cultural. Finalmente, por ter hoje o privilégio de realizar uma conferência na Faculdade de Direito do Largo de São Francisco, a mais antiga e, sem dúvida, a mais prestigiada entre todas as escolas jurídicas do Brasil. Não acrescentarei às razões do meu contentamento o fato de vir abordar aqui um tema de Direito Administrativo, porque seria tautológico ouvirem de um especialista uma declaração de amor à sua especialidade. Agradeço também, de forma particular, as palavras calorosas que o Professor Magano quis ter a bondade de me dirigir.

Falarei, pois, da evolução do Direito Administrativo em Portugal nos últimos dez anos. Não seguirei o método cronológico, mas tratarei o tema por assuntos. E desdobrarei esta palestra em três partes. $\mathrm{Na}$ primeira, referir-me-ei às modificações ocorridas na organização administrativa portuguesa. $\mathrm{Na}$ segunda, tratarei das alterações que incidiram sobre a regulamentação jurídica da atividade administrativa. $\mathrm{Na}$ terceira, ocupar-me-ei das modificações que tiverem por objeto as garantias dos particulares em face da Administração Pública.

(*) Gravação e transcrição pelo Professor Dr. Eduardo Lobo Botelho Gualazzi, Livre-Docente de Direito Administrativo da Faculdade de Direito da Universidade de São Paulo, com revisão do ilustre conferencista. 
Acrescento que, durante estas minhas considerações, citarei freqüentes vezes a Constituição portuguesa atual, porque ela é hoje uma das principais, senão a principal fonte do Direito Administrativo português

As mutações políticas têm sempre grande repercussão sobre as estruturas da organização administrativa. Foi assim em Portugal, em 1820, quando da nossa Revolução Liberal. Foi assim em 1910, quando da Proclamação da República. Foi assim também em 1974, por ocasião da Revolução de 25 de Abril.

O primeiro ponto que importa aqui sublinhar é o de que, por força da Constituição de 1976, se passou em Portugal de um sistema administrativo bastante centralizado para um sistema amplamente descentralizado. Segundo a Constituição de 1933, que vigorou até à queda do regime anterior, ao Governo competia exercer poderes administrativos sobre o conjunto da Administração Pública e, dentro desta, não se faziam quaisquer distinções, o que tinha sua lógica, pois havia um sistema de facto centralizado. Agora, porém, a Constituição distingue, dentro da Administração Pública, aquilo a que chama administração direta, administração indireta e administração autônoma. $\mathrm{E}$ a Constituição estabelece que o Governo tem poderes distintos em relação a estas três formas de Administração. $O$ Governo dirige os serviços da administração direta, superintende na administração indireta e exerce tutela sobre a administração autônoma.

Desde logo resulta deste esquema um princípio de descentralização e uma configuração pluralista de nossa Administração Pública. Em consequiência desta estruturação, que é conforme ao Estado democrático, a Constituição dá particular relevo àquilo que chama administração autônoma.

Sem fazer do Estado português um Estado de autonomias, como acontece hoje em dia com a Espanha, não há dúvida de que a nossa Constituição de 1976 marca a passagem de uma Administração centralizada e fortemente hierarquizada para uma Administração Pública descentralizada, com largas zonas de autonomia. Assim, em primeiro lugar, a Constituição prevê e autoriza a existência de associações públicas, modalidade que legitima a existência de certas organizações de tipo corporativo, como as ordens profissionais, organismos-base da lavoura, etc.

Em segundo lugar a Constituição constrói o conjunto das autarquias territoriais como um verdadeiro e próprio «poder local». Neste caso, onde o regime anterior nos dera apenas autarquias territoriais sujeitas ao controle político do Estado através da longa manus do Governo, que nomeava e demitia livremente os Presidentes das Câmaras (que aqui no Brasil são os Prefeitos), o novo regime veio restabelecer a tradição portuguesa dos magistrados municipais eleitos, verdadeiros representantes das populações locais junto do Poder 
central, e não agentes do Poder central junto das comunidades locais. À eleição livre dos corpos administrativos somou-se uma generosa e ousada lei das finanças locais, que reforçou consideravelmente a margem efetiva de auto-administração que beneficia, atualmente, os nossos corpos administrativos. Por outro lado, a revisão constituciona] de 1982 foi ainda mais longe - em minha opinião, até, longe demais - ao proscrever quaisquer tipos de tutela de mérito sobre os atos das autarquias locais, que desde então ficaram submetidas apenas a uma mera tutela de legalidade.

Não há dúvida, pois, de que se caminhou muitíssimo, nos últimos dez anos, no sentido da autonomia do poder local. Esta evolução tem, porém, um ponto negro, que é a deficiente forma de organização do sistema de governo das Câmaras Municipais, que repousa sobre um sistema de tipo parlamentar, baseado na coligação forçada de todos os Partidos que recebem votos nas eleições locais, o que redunda numa má articulação entre o Executivo e o Legislativo municipal.

Em terceiro lugar, a Constituição criou, para os Açores e para a Madeira, a figura das Regiões Autônomas, pessoas coletivas de direito público com regime político-administrativo especial, incluindo - e este é o ponto mais interessante - poderes legislativos e órgãos de governo próprios. Foi-se, portanto, muito além da mera auto-administração, para consagrar-se, nestes casos, um regime de auto-governo. É uma experiência inovadora, que na generalidade dos aspectos tem sido positiva e que representa uma novidade na História da Administração Pública portuguesa.

Se, no plano da administração autônoma, as alterações introduzidas foram positivas, de modo geral, temos, no entanto, que chamar a atenção para que, no plano da administração direta e indireta do Estado, pouco se fez de inovador nos últimos dez anos. Quase nada se legislou em matéria de administração direta; e a Reforma Administrativa continua à espera de quem quiser meter ombros a tão difícil quão necessária tarefa.

Quanto aos institutos públicos - a que aqui no Brasil se chama regular seu estatuto jurídico, e assistimos a uma proliferação excessiva de «autarquias institucionais» - também nenhuma lei genérica veio do número desses organismos. Todos os meses foram criados uns quantos e hoje temos, nada mais, nada menos, num pequeno País como Portugal, cerca de novecentos organismos autônomos desse tipo, o que é obviamente um exagero.

Porém, a Constituição portuguesa não se contentou em adotar determinadas posições concretas no plano das estruturas administrativas. Ela proclamou também alguns princípios gerais, em matéria de organização administrativa. Esses princípios são os seguintes: princípio da desburocratização, princípio da aproximação dōs serviços às populações, princípio da participação dos interessados na gestão da Admi- 
nistração Pública, princípio da descentralização e princípio da desconcentralização.

Este enunciado não tem apenas caráter programático, pois além de vincular o legislador ordinário a pôr em execução as diretivas que emanam daqueles princípios, ele tem ainda o efeito de tornar inconstitucionais todas as normas da legislação ordinária que porventura contrariem as orientações implícitas em tais princípios. $\mathrm{E}$ assim, por exemplo, que, em minha opinião, vários decretos-leis publicađos nos últimos anos, em Portugal, que transferem para o Estado determinadas atribuições municipais, são diplomas feridos de inconstitucionalidade material, porque ofendem o princípio da descentralização. $O$ legislador ordinário tem liberdade de avançar mais depressa ou mais devagar no sentido apontado pela Constituição, mas não pode arrepiar caminho e retroceder no sentido oposto.

Manda a verdade que se diga que muito pouco tem sido feito para dar plena execução aos princípios teóricos proclamados desde $1976 \mathrm{em}$ nosso texto constitucional: a desburocratização, ensaiada desde há anos, com êxito, aqui no Brasil, ainda não deu entre nós os primeiros passos; a aproximação dos serviços às populações tem sido praticamente letra morta; a participação dos interessados na gestão da Administração Pública não passa de um ideal distante; enfim, a descentralização e a desconcentração são objetivos para cuja consecução foram nomeadas pelo Governo, há mais de três anos, comissões especializadas que até hoje nada fizeram de positivo.

Podemos, pois, concluir, quanto a esta primeira parte, relativa à organização administrativa portuguesa, que as reformas efetuadas e os princípios gerais proclamados nos últimos dez anos estão certos, mas a distância que falta percorrer para os implantar na prática é enorme.

\section{II}

E passo à segunda parte de minha exposição, relativa à atividade administrativa. O domínio das normas aplicáveis à regulamentação da atividade administrativa é sobretudo marcado pelas regras relativas ao ato administrativo. Essa é a figura paradigmática da teoria geral da atividade administrativa. Ora, o Direito Administrativo português evoluiu bastante, nos últimos dez anos, em matéria de ato administrativo.

Desde logo, houve alterações importantes no próprio conceito de ato administrativo. Com efeito, o conceito tradicional de ato administrativo, que foi forjado para servir de base à delimitação do objeto do recurso contencioso de anulação (num sistema do tipo francês, como o português), tinha como elemento essencial, entre outros, a prática do ato administrativo por um órgão da Administração. Ficavam, assim, excluídas do conceito todas as decisões, ainda que materialmente 
administrativas, tomadas por outros órgãos do Estado que não fossem elementos integrantes da Administração Pública. Assim, por exemplo, os atos praticados em matéria administrativa pelo Presidente da República, pela Assembléia da República, pelos Tribunais Judiciais, pelos presidentes de outros Tribunais, pelo Procurador Geral da República, etc., mesmo que fossem atos materialmente administrativos, não eram organicamente administrativos, não provinham de órgãos da Administração e, por isso, não cabiam no conceito de ato administrativo. Em consequiência, deles nẳo havia recurso contencioso. Ora, o Estatuto dos Tribunais Administrativos, publicado em 1984, veio expressamente admitir recurso contencioso de todos estes atos, isto é, todos os atos materialmente administrativos, praticados, embora, por órgãos que não sejam órgãos da Administração Pública. É uma questão ainda em aberto saber se estes atos materialmente, mas não organicamente administrativos, são autênticos atos administrativos e se, portanto, foi o próprio conceito de ato administrativo que se alargou, ou se não o são, tendo-se apenas ampliado o âmbito do objeto possível do recurso contencioso de anulação. Pessoalmente, inclino-me para a segunda interpretação, por razões que não vou agora desenvolver; mas é inegável que houve aqui uma alteração importante no nosso sistema, que alargou as garantias da legalidade ao dispor dos cidadãos.

Outra inovação de grande relevo, e mais importante ainda que a anterior, foi o estabelecimento das chamas garantias de imparcialidade da Administração Pública, na prática de atos administrativos e na celebração de contratos por fazer um decreto- lei de 1983. Trata-se de um conjunto de normas do maior significado no combate à corrupção. Segundo essas normas, nenhum órgão ou agente administrativo pode praticar um ato, celebrar um contrato ou intervir num processo, se nele tiver interesse ou quando nele estiver envolvido seu cônjuge, parentes ou afins, sob pena de procedimento disciplinar contra o agente e da invalidade do ato praticado. Já existiam algumas normas dispersas sobre esta matéria no velho Código Administrativo de 1936/40, mas o diploma de 1983 vem agora alargar muito a incidência objetiva e subjetiva dos motivos de escusa e suspeição na atividade administrativa.

Outro capítulo em que as garantias dos particulares, relativas à formação do ato administrativo, eram insuficientes é a do chamado ato tácito. Duas eram as principais dificuldades práticas que o regime estabelecido em 1956 levantava sobre esta matéria. Por um lado, os prazos para impugnação do ato tácito eram demasiado curtos - apenas trinta dias em sequiência da produção automática do ato tácito. Por outro lado, a lei considerava que $o$ ato de indeferimento expresso que recaísse sobre um ato de indeferimento tácito se devia considerar ato confirmativo e, portanto, contenciosamente irrecorrivel. Ora, um decreto-lei publicado em 1977, com o objetivo expresso de reforçar as garantias dos particulares em face da Administração Pública, veio alterar estes dois pontos, na medida em que, por um lado, estabeleceu o prazo de um ano para a impugnação de atos tácitos, e em que, por outro lado, considerou que $o$ ato expresso de indeferimento que porventura recaia 
sobre um ato tácito anteriormente produzido não é confirmativo $\mathrm{e}$, portanto, pode ser contenciosamente recorrivel. Também aqui, desta maneira, foram consideravelmente alargadas as garantias dos particulares.

Ainda outro ponto importante diz respeito ao chamado dever de fundamentar os atos administrativos. O anterior Direito Administrativo português, tal como de resto a generalidade dos sistemas jurídicos europeus, não impunha aos órgãos da Administração Pública, como regra geral, o dever de fundamentarem as suas decisões: essa obrigação só existia nos casos em que a lei especialmente a impusesse. Ora, a ausência de um dever de fundamentar as decisões tomadas pela Administração Pủblica alarga desmensuradamente o âmbito e a intensidade do poder discricionário da Administração: recusar pura e simplesmente a petição de um particular é fácil; mais difícil e, por vezes, impossivel é recusá-la fundamentadamente, isto é, recusá-la dando as razões de facto e de direito que justificam essa recusa. Ora, o mesmo diploma de 1977 a que há pouco me referi veio impor o dever de fundamentar em relação à generalidade dos atos administrativos e, em particular, àqueles que neguem, extingam, restrinjam ou de qualquer modo afetem direitos ou interesses legítimos dos particulares, que impunham ou agravem deveres, encargos ou sanções, que decidam em contrário de pretensão formulada por interessado ou em contrário de parecer, informação ou proposta oficial, e ainda àqueles que decidam de modo diferente da prática habitualmente seguida na resolução de casos semelhantes ou na interpretação e aplicação de preceitos idênticos. Este dever de fundamentar os atos administrativos, que se aplica tanto aos atos escritos como aos atos praticados sob forma oral, implica que, no cumprimento deste dever, a Administração deve esclarecer concretamente a motivação do ato que praticou. $\mathrm{E}$ não pode a motivação ser obscura, contraditória ou insuficiente: a lei exige uma fundamentação clara, coerente e completa. Se ela não o for, o ato estará inquinado por vício de forma, e será anulável.

Finalmente, o artigo 268, $\mathrm{n}^{\circ}$ 2, da Constituição portuguesa veio reforçar a necessidade de notificação dos atos administrativos a seus destinatários, desde que não tenham de ser atos oficialmente publicados. O regime é, portanto, o seguinte: ou a lei impõe a obrigação de publicar o ato ou, então, ele só é eficaz em relação aos particulares se estes forem expressamente notificados.

Estas são as mais importantes alterações que foram introduzidas no Direito Administrativo português, nos últimos dez anos, quanto ao regime dos atos administrativos. Outra seria bem necessária e urgente e, aliás, constitucionalmente imposta, mas nem a Assembléia da República, nem os diferentes Governos foram capazes, até hoje, de a pôr cá fora. Refiro-me à publicação de um Código de Processo Administrativo Gracioso, ou de Processamento ou Procedimento Administrativo. De facto, há um artigo da nossa Constituição, o artigo 267, n 4, que estabelece que «o processamento da atividade administrativa será objeto 
de lei especial, que assegurará a racionalização dos meios a utilizar pelos serviços e a participação dos cidadãos na formação das decisões ou deliberações que lhes dissessem respeito. E o artigo 268, n' 1 acrescenta que «os cidadãos têm o direito de ser informados pela Administração, sempre que o requeiram, sobre o andamento dos processos em que sejam diretamente interessados, bem como o de conhecer as resoluções definitivas que sobre eles forem tomadas. Estas disposições constitucionais, porém, têm sido letra morta. É certo que, em 1980, foi elaborado um projeto de Código de Processo Administrativo Gracioso, como o chamamos nós, em Portugal, em cuja revisão tive a honra de participar, e que depois foi divulgado e submetido à discussão pública. Desta discussão pública resultou uma segunda versão, publicada em 1983. De então para cá, porém, nada mais se avançou e as duas versões repousam inertes nas gavetas governamentais. Ora, numa ou noutra das versões, a publicação de um diploma deste tipo é absolutamente indispensável. Só desse modo se passará, verdadeiramente, da Administração Pública burocrática, hierárquica, do tipo quase militar, que o modelo napoleônico nos legou, para uma Administração Pública moderna, participada, democrática, que o 25 de Abril prometeu, mas ainda não cumpriu.

Ainda no domínio da atividade administrativa, a última matéria que se faz mister sublinhar aqui é a dos príncipios constitucionais aplicáveis ao exercicio do poder administrativo. Quase todos esses princípios, formulados inicialmente pela doutrina e pela jurisprudência, estão hoje consagrados na Constituição portuguesa. Alguns deles são princípios tradicionais, cujo enunciado explícito não traz grande novidade: refiro-me ao princípio da prossecução do interesse público, ao princípio do respeito pelos direitos e interesses legítimos dos particulares, e ao princípio da legalidade. Há, contudo, dois outros princípios que nem a doutrina nem a jurisprudência portuguesas tinham ainda acolhido de modo generalizado e que a nossa Constituição veio formular em termos inovadores: o princípio da justiça e o princípio da imparcialidade. A importância especialíssima destes dois princípios reside no facto de que eles consubstanciam limites intrínsecos do poder discricionário da Administração, isto é, são critérios que devem nortear o exercício do poder administrativo e que, quando desrespeitados, geram a ilegalidade do ato administrativo praticado.

Não posso alongar-me aqui demasiado sobre este ponto, mas gostaria de dizer o seguinte. O princípio da justiça é entendido, em Portugal, como aquele princípio segundo o qual os órgãos e os agentes da Administração Pública devem atuar com justiça no exercício de suas funções. Desdobra-se em três corolários: o princípio da justiça em sentido estrito, o princípio da igualdade e o princípio da proporcionalidade, todos eles expressamente consagrados na Constituição portuguesa. Quanto ao princípio da imparcialidade, ele é entendido como o princípio segundo o qual os órgãos e os agentes da Administração Pública devem atuar com imparcialidade no exercício de suas funções. $\mathrm{E}$ 
desdobra-se também em três corolários: a proibição de favoritismos ou perseguições de natureza política, religiosa ou sindical, a proibição de decidir sobre o assunto em que órgão ou agente administrativo seja interessado e a proibição de tomar parte ou interesse em contratos celebrados com a Administração ou por ela aprovados ou autorizados.

Qual o significado da adoção destes princípios? Durante muito tempo, entendeu-se em Portugal que o único limite intrínseco do poder discricionário da Administração era constituído pelo fim do ato administrativo. O fim era sempre vinculado e o afastamento da Administração, em relação ao fim legal, traduzia-se numa ilegalidade do ato a que chamávamos «desvio de poder». O desvio de poder era, assim, o único vício característico do exercício ilegal do poder discricionário. (Chamo a atenção, entre parênteses, para o fato de que, em Portugal como em França, há um catálogo legal dos vícios do ato administrativo, que constituem outras tantas aberturas do recurso contencioso de anulação). Ora, esta perspectiva, que sumariamente lhes descrevi, sofreu uma alteração radical com a introdução na Constituição dos principios da justiça e da imparcialidade, porque agora a violação destes princípios, no exercício do poder discricionário, já não constitui matéria de administração pura, mas matéria de administração contenciosa. Já não é assunto que releve da esfera da discricionariedade, mas da esfera da vinculação. Já não traduz má administração, mas ilegalidade. $\mathrm{E}$, assim, o ato administrativo que viole o princípio da justiça é um ato administrativo ilegal; e o mesmo se passa com o ato que viole o princípio da imparcialidade. De modo que o exercício do poder discricionário já pode agora ser fiscalizado contenciosamente e o desvio de poder já não é a única ilegalidade que pode afetar um ato administrativo discricionário. A violação do princípio da justiça ou do princípio da imparcialidade, bem como a violação de qualquer de seus corolários, gera o vício de «violação de lei», distinto do vício de «desvio de poder».

Daqui resulta uma transformação muito importante no Direito Administrativo português. Até agora, analisávamos o ato administrativo em dois hemisférios: o hemisfério da legalidade e o hemisfério do mérito. No primeiro, tratava-se de averiguar da conformidade do ato das leis em vigor; no segundo, de averiguar da justiça e da conveniência do ato praticado. Um ato injusto ou inconveniente não era um ato ilegal; era apenas um ato ferido de um vício de mérito, meramente fiscalizável pelas autoridades da Administração ativa e não pelos Tribunais. Atualmente, por força do princípio da justiça consagrado na Constituição, um ato injusto passou a ser um ato ilegal e, portanto, passou a poder ser contenciosamente impugnável. A injustiça passou a poder ser apreciada e declarada pelos Tribunais Administrativos, constituindo fundamento de anulação do ato por ela inquinado. Quer dizer, em duas palavras, que a justiça transitou do hemisfério do mérito para o hemisfério da ilegalidade. 
$\mathrm{E}$ isto é uma revolução no mundo jurídico português. Mas é uma revolução que, afinal, tem todo o sentido: quem, melhor que os Tribunais, que são os templos da Justiça, pode apreciar se um ato administrativo é justo ou injusto? Com esta alteração, atingiu-se o ponto mais alto das mutações do Direito Administrativo português, nos últimos dez anos, bem dignas de uma Revolução que se anunciou libertadora e ao serviço do Estado de Direito. A prática jurídica, quer administrativa, quer judicial, ainda não se apercebeu inteiramente desta transformação e do seu alcance profundo, mas é inevitável que, com o tempo, isso acabará por acontecer.

\section{III}

Passo agora ao terceiro capítulo desta exposição, relativo às garantias dos particulares.

A primeira alteração que foi introduzida no sistema de garantias dos particulares foi a abolição daquilo a que, na tradição francesa, se chamava, em Portugal, a garantia administrativa, que era aquele instituto que fazia depender de autorização hierárquica o procedimento criminal contra qualquer agente administrativo argüido da prática de um crime no exercício de suas funções. Acontecia isto sobretudo no campo da atividade policial. Se um agente da Polícia, no exercício de suas funções, praticava um crime, só podia ser objeto de procedimento criminal se o Governo, através do Ministro do Interior, desse a devida autorização. Este regime levou a alguns abusos e, por isso, logo em seguida ao 25 de Abril, foi eliminada a garantia administrativa. Reação porventura excessiva! A meu ver, teria sido preferivel jurisdicionalizar esta garantia administrativa, em vez de a suprimir. A verdade é que foi suprimida.

A segunda inovação a assinalar foi a criação de um órgão chamado Provedor de Justiça, que corresponde àquilo que nos países escandinavos se chama o Ombudsman - instituição cuja razão de ser originária, como todos sabem, é proporcionar aos cidadãos uma alta autoridade, independente do Poder Executivo, eleita por maioria alargada no Parlamento, que fica habilitada a apreciar as queixas que os cidadãos apresentem contra o funcionamento dos Poderes Públicos, designadamente nos casos de má administração ou de atuação com vícios de mérito, casos esses que, por definição, não podem ser apreciados pelos Tribunais. A idéia, portanto, é a de criar um novo meio de garantia dos particulares, que combine simultaneamente o estatuto de independência e de isenção, próprio dos juízes, com o poder de conhecer do mérito da ação administrativa, característico das autoridades da Administração activa. O Provedor de Justiça foi bem acolhido pelo nosso meio e firmou já a sua autoridade e o seu prestígio na ordem jurídica e na vida pública portuguesa.

Contudo, merece dois reparos, em minha opinião, a organização concreta que as leis e a prática lhe têm vindo a dar. Por um lado, 
mercê de grandes atrasos acumulados pelos Tribunais Administrativos, em matéria de recurso contencioso o Provedor de Justiça é constantemente solicitado a apreciar queixas de natureza jurídica e a pronunciar-se sobre questões de legalidade estrita, o que desvirtua o seu objetivo essencial, que não é o de apreciar questões de legalidade, mas sim questões de mérito. Por outro lado, o relatório anual apresentado pelo Provedor de Justiça à Assembléia da República (que é o nome do Parlamento português) não é objeto da atenção e do cuidado que por sua natureza mereceria. Noutros países europeus, como, por exemplo, a Inglaterra, existe uma comissão parlamentar, especialmente encarregada de examinar os relatórios do Ombudsman, e a essa comissão são chamadas a depor as autoridades administrativas que não tenham dado seguimento às recomendações do Ombudsman: é fácil imaginar a chuva de perguntas, de críticas e de protestos da parte dos Deputados, em relação aos órgãos da Administração que não tenham cumprido as recomendações, e a difícil situação em que esses órgãos ficam colocados perante a comissão parlamentar. Em França, para além de uma comissão parlamentar desse tipo, há um serviço especial, junto do Primeiro Ministro, que tem por missão averiguar, de forma permanente e sistemática, sobre o seguimento dado pelos diferentes Ministérios a recomendações do órgão do mesmo tipo que lá existe e que, em França, se chama Médiateur. Ora, em Portugal, não existe nem uma coisa nem outra. Em minha opinião, para se tirar pleno rendimento do Provedor de Justiça, torna-se necessário adotar ambas as soluções - a comissão parlamentar e os serviços de acompanhamento junto do Primeiro Ministro. Só assim se evitará que a Administração ativa se sinta pouco motivada para cumprir as recomendações que lhe são dirigidas pelo Provedor de Justiça; só assim se tirará desta instituição toda a utilidade que ela pode dar.

Enfim, várias e importantes alterações marcaram os últimos dez anos, em Portugal, em matéria de contencioso administrativo. Sabem que, em Portugal, existe um contencioso administrativo de tipo francês: há uma jurisdição especializada de Tribunais Administrativos, que são encarregados de apreciar as questões surgidas entre a Administração Pública e os particulares, nomeadamente no tocante à anulação dos atos administrativos ilegais praticados pela Administração Pública. Duas inovações tiveram lugar em 1977, por força daquele diploma de que já falei várias vezes, publicado com o objetivo de reforçar as garantias dos particulares. Uma delas foi uma boa inovação. A outra foi má.

Foi boa a inovação que consistiu em dar nova regulamentação ao problema da execução das sentenças proferidas pelos Tribunais Administrativos contra a Administração Pública. Foi traçado novo regime jurídico, em alguns pontos inspirado no Direito Brasileiro. E permitam-me que faça aqui um parênteses de ordem pessoal, para congratular-me com o fato, porque eu tinha estudado algumas particularidades do regime jurídico vigente no Brasil sobre esta matéria, tinha 
referido a esse regime no capítulo do Direito Comparado da minha dissertação de Doutoramento e tive, em 1977, o prazer de verificar que as propostas que fiz, baseadas ou inspiradas no Direito, foram acolhidas pelo legislador português. Refiro-me, designadamente, ao regime jurídico que consiste em atribuir ao Poder Judicial, e não ao Poder Executivo, a responsabilidade pelo pagamento de quantias em dinheiro resultantes de sentenças condenatórias das administração Pública. É uma solução que vem jả de há algumas décadas, em diferentes Constituições Brasileiras e que, por essa inspiração, ficou na lei portuguesa redigida da seguinte forma: «No orçamento das pessoas coletivas públicas, será inscrita obrigatoriamente uma dotação destinada ao pagamento de encargos resultantes de sentenças de quaisquer Tribunais. As dotações a que se refere este artigo ficam à ordem do Conselho Superior da Magistratura, que emitirá a favor dos respectivos credores as ordens de pagamento que lhe forem requisitadas pelos tribunais, observando, no caso de insuficiência de verba, e enquanto esta não for devidamente reforçada, a ordem transito em julgado das sentenças».

Só que esta disposição nunca foi cumprida, até hoje: vemos, assim, como as melhores intenções ficam, por vezes, por realizar e como o «Diário da República» não passa, tantas vezes, de um cemitério de ilusões. $\overline{\mathrm{E}}$, a meu ver, indispensável e urgente tomar providências para que esta disposição legal seja efetivamente cumprida.

Outra inovação foi estabelecida em 1977 e, essa, eu a considero negativa. Tratou-se de instaurar aquilo a que se chama a reclamação prévia necessária, como condição de interposição de qualquer recurso contencioso, solução inspirada no Direito alemão e que consiste em estabelecer que, antes de recorrer a Tribunal, o particular deve expor as suas razões de queixa à própria Administração, à própria autoridade que praticou $o$ ato ilegal, e somente após ela reexaminar esse ato é que, então, poderá recorrer a Tribunal no caso de a Administração não ter revogado o ato impugnado. Com esta alteração, pretendeu-se fundamentalmente aliviar o funcionamento dos nossos Tribunais Administrativos, que estão muito sobrecarregados, retendo no crivo da própria Administração ativa os processos que pudessem ser por ela decididos, sem necessidade de julgamento pelo Tribunal. A intenção era boa. Só que não se contou com a má formação de grande parte dos órgãos e agentes da Administração. $\mathrm{E}$ o resultado foi que, em grande número de casos, a Administração Pública nem aprecia a reclamação prévia necessária, nem remete o processo ao Tribunal, atrasando assim gravemente, e por vezes mesmo impedindo, o funcionamento da Justiça Administrativa. O que procurava ser uma medida de reforço da garantia dos particulares converteu-se, assim, em poucos anos, numa diminuição de garantias. Toda a doutrina administrativa portuguesa protestou sistemática e vigorosamente contra esta solução. Há dois meses, no dia 16 de julho, tivemos a satisfação de ver publicado um diploma, no Diario da República, que finalmente aboliu esta estranha solução e restabeleceu o sistema pelo qual os particulares, quando querem impugnar contenciosamente um ato ilegal, se devem dirigir di- 
retamente ao Tribunal competente, sem passar pela via da reclamação prévia necessária, junto da Administração ativa.

Em 1984, o Governo publicou uma profunda reforma dos Tribunais Administrativos - reforma positiva, que em muitos pontos veio dar satisfação às reinvidicações da doutrina e da jurisprudência, mas que teve também o inconveniente, em minha opinião, de não permitir descongestionar, de maneira eficaz e satisfatória a sobrecarga de trabalho em que se encontram os Tribunais Administrativos portugueses, neste momento. Basta dizer que a situação atual é a de que, no conjunto dos Tribunais Administrativos portugueses, entram anualmente dois mil recursos de anulação e são julgados apenas mil, o que dá idéia do agravamento que anualmente se vai processando no funcionamento da Justiça. Esta reforma que foi feita em 1984 para dar satisfação a esse problema efetivamente não conseguiu resolvê-lo e a acumulação de trabalho, nos Tribunais Administrativos, vai continuar a demorar cada vez mais a realização da justiça na relação entre os cidadãos e a Administração Pública.

$\hat{E}$ um problema grave, que enfrentamos neste momento, porque a produtividade e a eficiência dos Tribunais Administrativos é uma condição da eficácia das garantias dos particulares em face da Administração Pública, no Estado de Direito. De nada adianta proclamar o Estado de Direito se as garantias jurisdicionais não funcionam plenamente a tempo e hora. De nada serve proclamar a existência de garantias jurisdicionais se os Tribunais encarregados de efetivá-las recebem dois mil processos por ano e julgam anualmente mil processos, apenas. De nada vale proclamar um autêntico contencioso administrativo se os recursos de anulação, que deviam ser decididos num ano ou no máximo em dois, levam quatro, cinco ou seis anos a concluirem-se.

$\mathrm{E}$ com isto termino. Como não podia deixar de ser, o restabelecimento da democracia em Portugal trouxe consigo vastas e importantes reformas da legislação administrativa, que cobriram todas as áreas do Direito Administrativo - a organização, a atividade, as garantias. Muitos passos de grande significado foram dados em direção ao aperfeiçoamento do Estado de Direito, mas há ainda muito que fazer para atingir os níveis que hoje se praticam em outros países europeus, mais evoluídos nesta matéria, como a França ou a República Federal Alemã.

Há sobretudo que estar atento ao vício caracteristicamente português de legislar no vácuo, sem cuidar de assegurar a efetiva execução do Direito legislado. Cria-se um Provedor de Justiça, mas nem a Assembléia da República, nem o Governo, se debruçam sobre os seus relatórios. Generaliza-se a toda a Administração o dever de fundamentar as decisões, mas não se vela pelo cumprimento dessa obriga- 
ção. Institui-se um sistema muito avançado de garantia da execução das sentenças dos Tribunais Administrativos, mas não se obriga os Ministros das Finanças a cumprir as normas respectivas. Enfim, procede-se a uma reforma dos Tribunais Administrativos, mas confessa-se, logo à partida, que ela não será eficaz, nem resolverá o problema principal que ditou sua publicação. Isto para já nâo falar no mau funcionamento da Administração Pública em tantos domínios, bem como na enorme deterioração da qualidade dos serviços que a Administração presta ao público.

Quer dizer: os portugueses, nos últimos dez anos, revelaram-se melhores no Direito Administrativo do que na Ciência da Administração; melhores juristas do que administradores; melhores na teoria do que na prática. O Direito Administrativo evoluiu bem, a Administração Pública e os Tribunais Administrativos evoluiram mal. O Direito Administrativo reforçou as garantias dos particulares, a prática administrativa e judicial manteve-as no nivel anterior, quando não as diminuiu efetivamente.

Ora, o Direito não é uma ordem teórica e conceptual, destinada a comprazer o exercício intelectual de meia dúzia de construtores de sistemas. O Direito é e tem de ser uma ordem normativa da vida prática quotidiana dos cidadãos e das empresas. Se as garantias dos particulares melhoraram muito em teoria, mas foram em muitos aspectos diminuídas na prática, poderemos em consciência dizer que a evolução foi positiva?

A resposta a esta pergunta encontramô-la num autor do Século XVIII, Edmund Burke, que nas suas reflexões sobre a Revolução em França, escreveu a dada altura: «Não posso congratular-me com o estabelecimento da liberdade, senão quando vir o uso que dela for feito. Tenho que suspender o meus parabéns sobre a nova liberdade da França até ser informado sobre o modo como ela for combinada com um bom Governo, com a ordem pública, com a disciplina e a obediência dos Exércitos, com a produção de um rendimento efetivo e bem distribuído, com a moralidade e a religião, com a paz e a ordem, com o civismo e os bons costumes. Todas estas coisas são também, à sua maneira, coisas boas e sem elas a liberdade pode não ser benéfica enquanto dura, e não é provável que dure muito. $O$ efeito da liberdade nos indivíduos consiste em que eles passam a poder fazer o que lhes apraz. $E$, pois, necessário ver o que é que na realidade lhes apraz, antes de nos arriscarmos a congratulações que depressa podem ter-se tornado em razões de queixa».

Eis o problema essencial da evolução do Direito Administrativo nos últimos dez anos, em Portugal. Analisado no «Diário da República», é motivo de congratulação; examinado na prática quotidiana, é razão de queixa. Converter esta situação e transformar as razões de queixa em motivos de congratulação é o objetivo por que os juristas portugueses terão de Iutar nos próximos dez anos. 